\title{
Comparative Study of Butorphanol versus Clonidine as an Adjuvant to Intra Thecal Hyperbaric Bupivacaine $0.5 \%$ for Lower Abdominal and Lower limb Surgeries
}

\author{
Vishva Darshanbhai Shah' ${ }^{1}$ Gargi Mayur Bhavsar², Jyotsna Sirohi ${ }^{3}$, Akash Jaysukhbhai Mulani ${ }^{4}$ Disha Himanshu Shah ${ }^{5}$ \\ 1, 2, 3, 4 Department of Anaesthesiology, N.H.L. Municipal Medical College, Ahmedabad, Gujarat, India. \\ ${ }^{5}$ Department of Anaesthesiology, AMCMET Medical College, Ahmedabad, Gujarat, India.
}

\section{ABSTRACT}

\section{BACKGROUND}

Spinal anaesthesia is frequently used for surgical procedures of lower-limb, pelvis, and lower-abdomen to provide adequate anaesthesia and analgesia. Bupivacaine is considered to be a standard drug as far as therapeutic and side-effect profiles are concerned. Clonidine, a selective $\alpha-2$ adrenergic blocker, is a potent analgesic and free from opioid related side-effects. Butorphanol, an opioid with agonistic action on $\kappa$ receptors, antagonist and partial-agonist property at $\mu$-receptors, is less costly and widely available without restriction. We, therefore, conducted this study to evaluate efficacy of butorphanol and clonidine as adjuvants to bupivacaine in elective lowerabdominal and lower-limb surgeries.

\section{METHODS}

60 patients of American Society of Anaesthesiologists (ASA) class I and II of age group 18 - 58 years of either sex, undergoing elective lower-abdominal and lower-limb surgeries were selected and allocated in to 2 groups. Group-I received $45 \mu \mathrm{g}$ of clonidine and group-II received $300 \mu \mathrm{g}$ of butorphanol with hyperbaric bupivacaine $0.5 \% 1.6 \mathrm{mg}$ bupivacaine $(3.2 \mathrm{~mL})$. Patients were assessed in terms of time of onset of sensory and motor block, perioperative haemodynamic stability, duration of sensory and motor block, duration of analgesia and adverse effects.

\section{RESULTS}

The onset of sensory and motor block was $21.33+3.83 \mathrm{sec}$ and $40.1+3.35 \mathrm{sec}$ in patients receiving butorphanol. The onset of sensory and motor block was $65+9.7$ sec and $87+9.4 \mathrm{sec}$ in patients receiving clonidine. The duration of analgesia was $384.8+12.42 \mathrm{~min}$ in clonidine group and $313.93+9.23 \mathrm{~min}$ in butorphanol group.

\section{CONCLUSIONS}

Both clonidine and butorphanol are good adjuvants to hyperbaric bupivacaine for spinal anaesthesia. Butorphanol provides early sensory and motor onset as compared to clonidine whereas clonidine provides longer duration of sensory and motor blockade as well as prolonged duration of postoperative analgesia compared to butorphanol.

\section{KEY WORDS}

Spinal Anaesthesia, Butorphanol, Clonidine
Corresponding Author: Dr. Gargi Mayur Bhavsar, A-1 Sursagar Flats, 196/220 Aazad Society, Aambawadi, Ahmedabad - 380015, Gujarat, India.

E-mail: gargibhavsar@gmail.com

DOI: $10.14260 /$ jemds/2020/865

How to Cite This Article:

Shah VD, Bhavsar GM, Sirohi J, et al. Comparative study of butorphanol versus clonidine as an adjuvant to intra thecal hyperbaric bupivacaine $0.5 \%$ for lower abdominal and lower limb surgeries. J Evolution Med Dent Sci 2020;9(52):39563962, DOI: 10.14260/jemds/2020/865

Submission 08-09-2020, Peer Review 01-11-2020,

Acceptance 08-11-2020, Published 28-12-2020.

Copyright (C) 2020 Vishva Darshanbhai Shah et al. This is an open access article distributed under Creative Commons Attribution License [Attribution 4.0 International (CC BY 4.0)] 


\section{BACKGROUND}

Spinal anaesthesia is the fastest, most predictable and reliable form of regional anaesthesia. Spinal anaesthesia was first observed by August Bier ${ }^{1}$ in 1899 where a small mass of drug, virtually devoid of systemic pharmacologic effect, can produce surgical anaesthesia. However, haemodynamic instability due to sympathetic blockade impedes effective and safe use of spinal anaesthesia. These effects are proportional to the level of sympathetic blockade. Different anaesthetic techniques are employed to lower the incidence of the haemodynamic complications by using either the low dose of local anaesthetic agents or addition of adjuvants to local anaesthetics Advantages of spinal anaesthesia are offset by complain of post-operative pain when effect of local aesthesic wears off due to relatively shorter duration of action. Adjuvants are added to prolong the blockade. ${ }^{2}$

Bupivacaine is the most commonly used local anaesthetic in spinal anaesthesia. By adding a small dose of narcotics to local anaesthetic solution, the duration of anaesthesia and analgesia can be significantly prolonged. ${ }^{3}$ Yaksh and Rudy, in $1976,{ }^{4}$ were the first to demonstrate direct opioid analgesia at spinal cord level. In 1979, Wang et al. ${ }^{5}$ observed significant analgesia with 0.5 - $1 \mathrm{mg}$ spinal morphine.

The combination of local anaesthetic and adjuvants effectively inhibit multiple areas of neuronal excitability to provide a dose sparing effects of local anaesthetics. The analgesic effect of clonidine is mediated spinally through activation of post-synaptic $\alpha 2$ receptors in substantia gelatinosa of the spinal cord to enhance the sensory and motor blocks of local anaesthetics without increasing the incidence of side effects of respiratory depression. ${ }^{6,7}$ Clonidine is a potent analgesic and free from opioid-related side effects like pruritus, nausea, vomiting and urinary retention. It is known to increase both sensory and motor blockade.

Butorphanol exhibits partial agonist and antagonist activity at the $\mu$ opioid receptor as well as competitive antagonist activity and partial agonist activity at the $\mathrm{k}$ opioid receptor. Stimulation of these receptors on central nervous system neurons causes an intracellular inhibition of adenylate cyclase, closing of influx membrane calcium channels and opening membrane potassium channels. This leads to hyperpolarization of the cell membrane potential and suppression of action potential transmission of ascending pain pathways. Because of its $\mathrm{K}$ agonist activity, at analgesic doses butorphanol increases pulmonary arterial pressure and cardiac work. Additionally, k agonism can cause dysphoria at therapeutic or supratherapeutic doses; this gives butorphanol a lower potential for abuse than other drugs. Butorphanol is also quite effective at reducing postoperative shivering. Butorphanol is easily available without any restriction as compared to fentanyl and other opioids along with $\mathrm{H}$ schedule drug. ${ }^{8}$ Bupivacaine acts mainly by blockade of voltage gated $\mathrm{Na}+$ channels in the axonal membrane and presynaptic inhibition of calcium channels. A combination of these effects may explain the observed synergism between bupivacaine and clonidine / butorphanol characterized by enhanced somatic analgesia without affecting the cephalad spread of bupivacaine.

We conducted this study to evaluate the efficacy of butorphanol and clonidine as adjuvant to bupivacaine in elective lower-abdominal and lower-limb surgeries.

\section{METHODS}

On approval from institutional review board, we carried out this observational study on randomLy selected 60 patients of ASA grade I \& II, between 18 - 60 yrs. of age, of either sex undergoing elective surgery for lower-abdominal and lowerlimb procedures planned between May,2016 to May, 2018 with total duration of study period being 24 months. Sample size was chosen to be of 60 patients as they were eligible according to the inclusion criteria.

\section{Exclusion Criteria}

Patient refusal, patient with gross spinal deformity, pregnancy / lactation, known allergy to local anaesthetics, hypersensitivity to study drugs, local infection at the site, coagulation disorder, and ASA grade III, IV, V.

\section{Pre-Study Evaluation}

Pre-operative evaluation included detailed history, general and systemic examination. Vital parameters were noted (pulse, blood pressure, respiratory rate, oxygen saturation at room temperature). An informed valid written consent was obtained from each patient. On entering the operation theatre, non-invasive monitoring was initiated including oxygen saturation, electrocardiogram, end tidal $\mathrm{CO}_{2}$ and blood pressure. A peripheral venous access was secured on nondominant hand with 18-gauge cannula and preloading was done with lactated Ringer's solution 8 - $10 \mathrm{~mL} / \mathrm{kg}$ in within 20 - 30 min prior to subarachnoid block.

\section{Study Groups}

Patients were randomly divided in an unblinded manner into two equal groups of 30 patients each according to computer generated random number table

\section{Group BC}

Bupivacaine clonidine group. Here patients received $16 \mathrm{mg}$ bupivacaine heavy $(0.5 \%)(3.2 \mathrm{~mL})$ with $45 \mathrm{mcg}$ clonidine $(0.3$ $\mathrm{mL}$ ) (from $150 \mathrm{mcg} / \mathrm{mL}$ ampoule).

\section{Group BB}

Bupivacaine butorphanol group. Here patients received $16 \mathrm{mg}$ bupivacaine heavy $(0.5 \%)(3.2 \mathrm{~mL})$ with $300 \mathrm{mcg}$ butorphanol $(0.3 \mathrm{~mL})$ (from $1 \mathrm{mg} / \mathrm{mL}$ ampoule). All patients received total volume of $3.5 \mathrm{~mL}$ intrathecally. All patients were explained the linear visual analogue scale (LVAS) for pain during preanaesthetic check-up. LVAS used as $10 \mathrm{~cm}$ line where 0 denoted "no pain", while 10 denoted "worst pain imaginable". Quality of post-op analgesia was assessed using patient's interpretation of pain from LVAS. The surgical anaesthesia was considered effective when $\mathrm{T}_{6}$ dermatome was anaesthetized and Bromage grade III block was achieved. Intraoperatively heart rate, systolic blood pressure, diastolic blood pressure, mean arterial pressure, respiratory rate and oxygen saturation were recorded every 2 mins for first 15 mins, then every 15 mins for 2 hours, every 30 mins for 4 hrs., every 6 hrs. till 24 hrs. in postoperative ward. 
The following were observed

- Haemodynamic stability: heart rate, systolic blood pressure, diastolic blood pressure, mean arterial pressure.

- Respiratory parameters: respiratory rate and oxygen saturation.

- Onset of sensory and motor block.

- Time for highest sensory block and dermatomal level achieved.

- $\quad$ Time for motor block to reach modified Bromage grade 3 .

- Time for 2 segment regression of sensory level.

- $\quad$ Time for motor block to regress to Bromage grade 1.

- Time for sensory regression to $\mathrm{S}_{1}$ level.

- Time for $1^{\text {st }}$ analgesic demand post-operatively or when visual analogue scale score was $\geq 5$ whichever was first.

- Campbell's sedation score ${ }^{9}$ at $30 \mathrm{~min}$ and at $150 \mathrm{~min}$.

\section{Definitions}

\section{Hypotension}

Fall in systolic blood pressure by more than $30 \%$ from baseline value or systolic blood pressure $<90 \mathrm{mmHg}$. Treated with additional boluses of IV fluids, inj. mephentermine $6 \mathrm{mg}$ was given if hypotension persisted. ${ }^{10}$

\section{Bradycardia}

Heart rate $<60 /$ min or fall in heart rate $>30 \%$ from baseline value. It was treated with $0.6 \mathrm{mg}$ intra venous atropine.

\section{Respiratory Depression}

When respiratory rate was $<8$ / min or oxygen saturation $<90$ $\%$ on room air. Treated with $100 \% \mathrm{O}_{2}$ via Bain's circuit followed by $\mathrm{O}_{2}$ through face mask at the rate of $6 \mathrm{~L} / \mathrm{min}$.

\section{Onset of Sensory Block}

Start of tingling numbness. Highest level of sensory block and time to attain it were recorded. Further sensory testing was performed at 30 mins intervals till the recovery of $\mathrm{S}_{1}$ dermatome. Assessed by bilateral pin prick method time for regression of sensory block by 2 segments was also recorded.

\section{Onset of Motor Block}

Feeling of heaviness in lower limb. Motor block was assessed by using modified Bromage scale.

\section{Sedation Score}

Patients were assessed for degree of sedation and scoring was done with Campbell sedation score.

\section{Duration of Analgesia}

It was considered as interval from time of intrathecal injection to the time of $1^{\text {st }}$ analgesic demand post-operatively or when visual analogue scale score $>5$ since, it depicts moderate pain. Inj. diclofenac sodium was given as rescue analgesia.

The data obtained, was statistically analysed using unpaired student's t-test. Average percentage change in data over baseline values to detect trends.

\section{RESULTS}

\begin{tabular}{|c|c|c|c|c|}
\hline Parameter & Group BC & Group BB & $\begin{array}{l}\text { P Value } \\
\text { BC vs BB }\end{array}$ & Inference \\
\hline Onset of sensory block (sec) -t1 & $65+9.7$ & $21.33+3.83$ & $<0.0001$ & S \\
\hline Onset of motor block (sec) - $\mathrm{t} 2$ & $87+9.4$ & $40.1+3.35$ & $<0.0001$ & S \\
\hline $\begin{array}{l}\text { Time for peak sensory } \\
\text { block (mins) -t3 }\end{array}$ & $13.74+0.77$ & $5.4+0.62$ & $<0.0001$ & S \\
\hline $\begin{array}{l}\text { Time for peak motor block - } t 4 \\
\text { (Bromage g-3) (mins) }\end{array}$ & $4.56+0.35$ & $4.09+0.49$ & $<0.0001$ & S \\
\hline $\begin{array}{l}\text { Time for } 2 \text { segment sensory } \\
\text { regression (mins) -t5 }\end{array}$ & $113.7+14.2$ & $60.33+6.93$ & $<0.0001$ & S \\
\hline $\begin{array}{l}\text { Time for motor regression } \\
\text { (Bromage g-1) (mins) -t6 }\end{array}$ & $260+13.45$ & $231+8.55$ & $<0.0001$ & S \\
\hline $\begin{array}{l}\text { Time for sensory regression to } \\
\text { s1 (mins) -t7 }\end{array}$ & $301+14.11$ & $259+8.10$ & $<0.0001$ & S \\
\hline $\begin{array}{l}\text { Time for rescue analgesia } \\
\text { (mins) -t8 }\end{array}$ & $384.8 \pm 12.42$ & $\begin{array}{c}313.93 \pm \\
9.23\end{array}$ & $<0.0001$ & $\mathrm{~S}$ \\
\hline
\end{tabular}

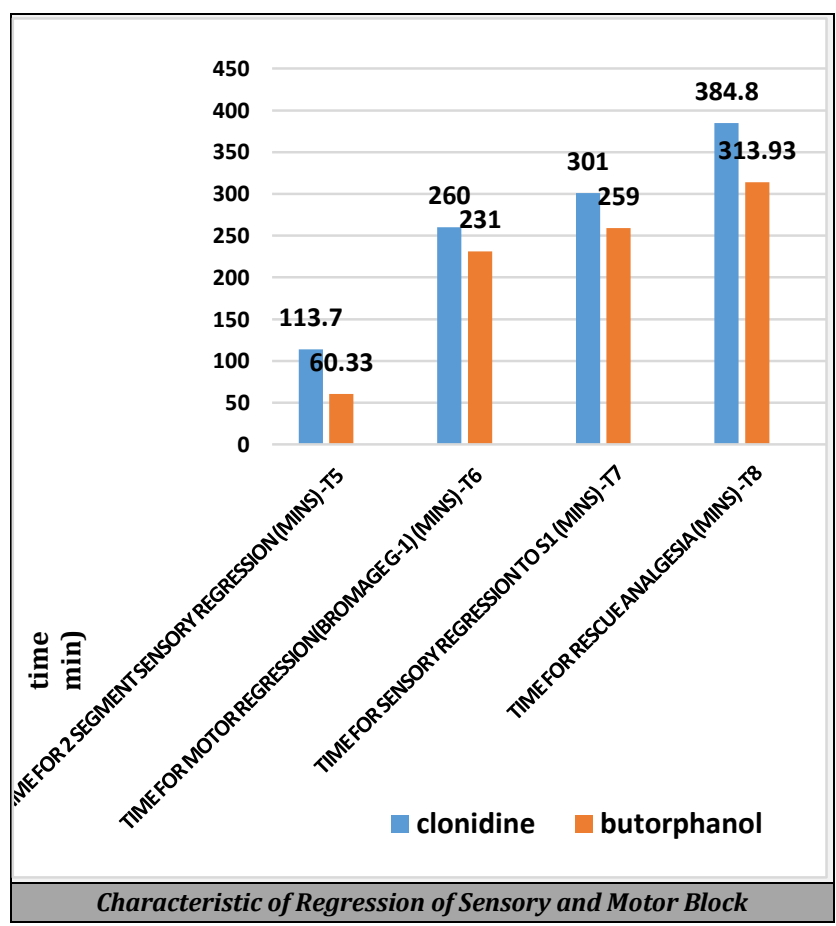

After studying 60 cases, observation and results are summarised in tabulated form and described below. Both groups comprised of 30 patients. No significant difference in age, sex ratio, ASA grading and duration of surgery was seen in both the groups. Both the groups were also comparable in context with type of surgeries.

Mean time of sensory onset (T1 $-21.33+3.83 \mathrm{sec})$ and motor onset (T2 $-40.1+3.35 \mathrm{sec})$, time to achieve peak sensory level (T3 $-5.4+0.62 \mathrm{~min})$ and time to achieve Modified Bromage grade 3 motor block (T4 - $4.09+0.49 \mathrm{~min}$ ) were shorter in butorphanol group (BB) compared to clonidine group (BC) and results were statistically significant.

Mean duration of sensory and motor block was also found to be statistically significant. Motor block being $260+13.45$ mins and sensory block being $301+14.11$ mins was longer in group BC than group BB. Mean time for requirement of rescue analgesia was observed to be significantly delayed in group BC (384.8 $\pm 12.42 \mathrm{mins}$ ) as compared to group BB (313.93 \pm 9.23 mins). 
The base line heart rate was comparable in both the groups. Significant change was noted in heart rate in group BC showing decrease in heart rate from 6 mins onwards up to 10 hrs of spinal anaesthesia with maximum decrease occurring at around 45 mins. Base line systolic blood pressure was comparable in both the groups. There was a statistically significant decrease in systolic blood pressure occurring at 15 min after spinal anaesthesia in group BC and remained lower compare to group BB up to 6 hours. Base line diastolic blood pressure was comparable in both the groups. There was a statistically significant decrease in diastolic blood pressure occurring at $30 \mathrm{~min}$ after spinal anaesthesia in group $\mathrm{BC}$ and remained lower compare to group BB up to 6 hours. Base line mean arterial pressure was comparable in both the groups. There was a statistically significant decrease in mean arterial pressure occurring at $30 \mathrm{~min}$ after spinal anaesthesia in group $\mathrm{BC}$ and remained lower compared to group BB up to 6 hours. No significant difference in respiratory rate was seen in either of the group.

\section{Complications}

A low incidence of complications was observed in our study. Patients in group BC were observed to have higher incidences of hypotension and bradycardia compared to group BB. In group BC 3 patients (10\%) developed bradycardia whereas in group BB only 1 patient (3.33\%) developed bradycardia. In group $\mathrm{BC}, 3$ patients (10 \%) were observed to have hypotension whereas in group $\mathrm{BB}$ none of the patients developed hypotension. Shivering was observed in only 1 patient (3.33\%) in group BC. None of the patients in group BB were observed to have developed shivering. None of the patients in both of the groups had developed nausea, vomiting, pruritus, urinary retention or respiratory depression. Mean time for visual analogue scale score $\geq 5$ in group $\mathrm{BC}$ was around $360 \mathrm{~min}(384+12.42 \mathrm{~min})$ whereas in group BB it was around $300 \mathrm{~min}(313.93+9.23 \mathrm{~min})$. This difference was found to be statistically highly significant. However, after rescue analgesia, no significant difference was seen among the groups during subsequent observations.
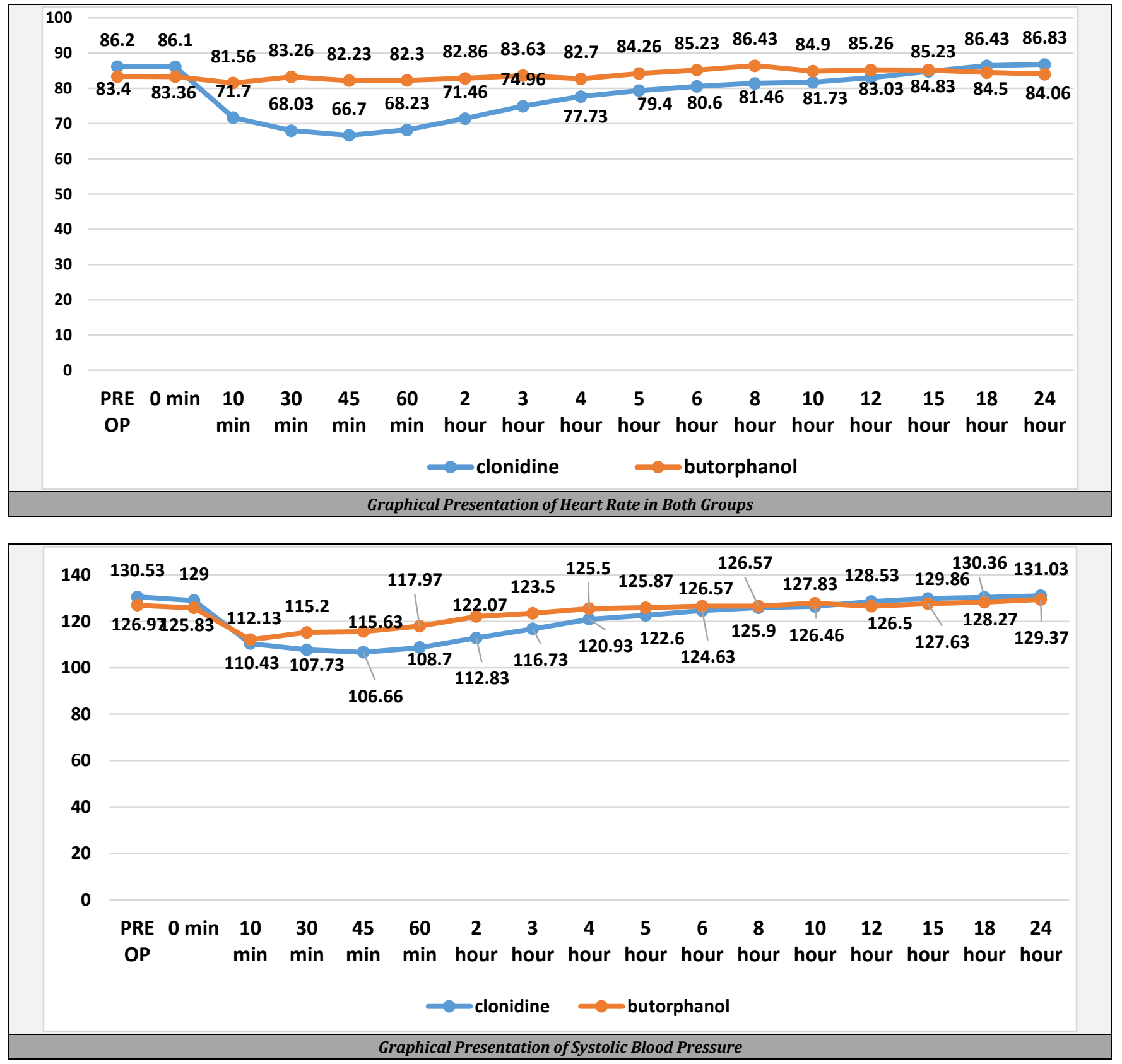


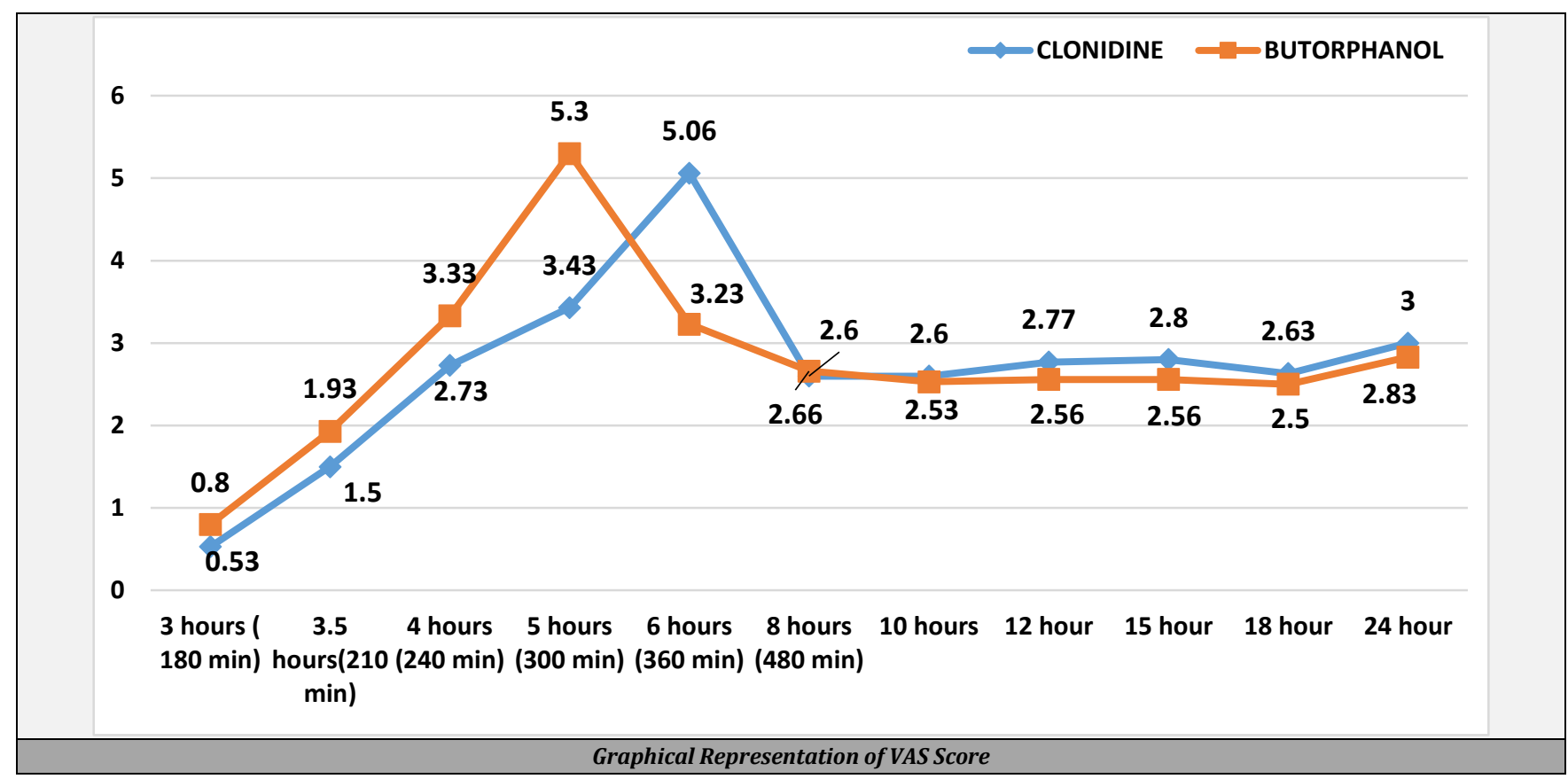

\section{Campbell's Sedation Score ${ }^{9}$}

At 30 mins Campbell's sedation score was $1.6+0.62$ in group $\mathrm{BC}$ and $0.5+0.50$ in group BB. At 150 mins the score was $1.4+$ 0.49 in group $\mathrm{BC}$ and $0.46+0.50$ in group BB. The difference between these 2 groups was statically significant with $p$ value $<0.0001$. Patients in $\mathrm{BC}$ group were more sedated compare to BB group intraoperative and postoperative. As per the table, the patients in group $\mathrm{BC}$ were sleeping comfortably but responding to verbal command. Patients in the study did not require any supplemental oxygen or did not have respiratory depression.

\section{DISCUSSION}

\section{Drug and Dose}

Kumkum Gupta et al. ${ }^{11}$ studied addition of butorphanol $200 \mu \mathrm{g}$ $(0.2 \mathrm{~mL})$ \& clonidine $30 \mu \mathrm{g}(0.2 \mathrm{~mL})$ to $3.5 \mathrm{~mL}$ bupivacaine for subarachnoid block in orthopaedic surgeries. Gopal Reddy et al. ${ }^{12}$ used $200 \mu \mathrm{g}$ of butorphanol and $20 \mu \mathrm{g}$ of fentanyl with 3 $\mathrm{mL}$ of bupivacaine. Subrata Nag et al. ${ }^{13}$ used $500 \mu \mathrm{g}$ of butorphanol in subarachnoid block.

We chose the doses of $300 \mu \mathrm{g}$ butorphanol $(0.3 \mathrm{~mL})$ and 45 $\mu \mathrm{g}$ of clonidine $(0.3 \mathrm{~mL})$, as this dose provided better postoperative analgesia with significantly lower side effects. Heavy volume of bupivacaine $(0.5 \%)$ was $3.2 \mathrm{~mL}$ in all cases in our study. Dosage was selected in a manner that total volume given in subarachnoid block remained same in both the groups; that is $3.5 \mathrm{~mL}$.

\section{Onset, Peak Sensory and Motor Blockade}

(Time for onset of sensory block was longer in group BC (65 \pm $9.7 \mathrm{sec})$ and group BB $(21.33 \pm 3.83 \mathrm{sec})$. Time to achieve highest sensory level was also longer in group BC $(13.74+0.77$ $\mathrm{min}$ ) and in group BB (5.4 $+0.62 \mathrm{~min})$. There was significant difference observed in onset of motor blockade in both the groups (group BC $87 \pm 9.4 \mathrm{sec}$ and group BB $40.1 \pm 3.35 \mathrm{sec}$ ) and time to achieve Bromage Grade 3 motor block (group BC
$4.56+0.35 \mathrm{~min}$ and group BB $4.09+0.49 \mathrm{~min}$ ) with time required for the given observation being longer in group $\mathrm{BC}$.

Kumkum Gupta et al, ${ }^{11}$ defined onset of sensory blockade as time from intrathecal injection to occurrence of sensory block at T10 level and observed that onset of sensory blockade was $3.4+1.7 \mathrm{~min}$ with clonidine $30 \mu \mathrm{g}$ and $3.91+2.2 \mathrm{~min}$ with $200 \mu \mathrm{g}$ butorphanol. Time to achieve highest sensory block was $7.4+2.7 \mathrm{~min}$ in clonidine group and $9.13+3.8$ in butorphanol group. Time taken to achieve complete motor block was $11.23+2.7$ min with clonidine and $12.9+3.2 \mathrm{~min}$ with butorphanol.

\section{Duration of Sensory and Motor Block}

In our study, duration of sensory and motor block was longer with clonidine $(260+13.45 \mathrm{~min}$ and $301+14.11 \mathrm{~min})$ as compared to that of butorphanol $(231+8.55 \mathrm{~min}$ and $259+$ $8.55 \mathrm{~min})$.

Kumkum Gupta et al.11 observed total duration of sensory and motor block with clonidine was $316.7+29.6 \mathrm{~min}$ and $310.63+26.05 \mathrm{~min}$ respectively. Total duration of sensory and motor block with butorphanol was $278.6+23.88 \mathrm{~min}$ and 283 +39.63 min respectively. Duration was longer in clonidine group as compare to butorphanol group which is correlated to our study. However, duration of motor and sensory block was longer in their study compare to our study which can be attributed to higher volume of bupivacaine in their study.

Anandani $\mathrm{DN}^{14}$ et al., observed total duration of sensory block was $258.66+35.93$ min and motor block was $305.33+$ $36.91 \mathrm{~min}$ in clonidine group in their study.

\section{Duration of Analgesia}

Both the adjuvants used in our study lead to decrease in pain score and reduced analgesic requirement in the postoperative period. In our study, we observed that total duration of analgesia was significantly prolonged in group BC (384.8+ $12.42 \mathrm{~min})$ compared to group BB $(313.93+9.23 \mathrm{~min})$.

Kumkum Gupta et al.,11 observed duration of analgesia was $278.7+29.6 \mathrm{~min}$ in clonidine group and $218.6+21.9 \mathrm{~min}$ in 
butorphanol group. They observed that total duration of analgesia was significantly longer with clonidine as compare to butorphanol. This difference in observation was comparable to the observation in our study.

\section{Haemodynamic Parameters \& Side Effects / Complications}

In our study all the hemodynamic parameters (pulse, blood pressure, MAP, Respiratory rate \& Sp02) of both the groups were comparable at initial baseline values and were clinically \& statistically insignificant. Heart rate decreased in both the group but statistically significant change was noted in heart rate in group $\mathrm{BC}$ showing decrease in heart rate from 6 mins onwards up to $10 \mathrm{hrs}$ of spinal anaesthesia with maximum decrease occurring at around 45 mins. Blood pressure also decreased in both groups, but magnitude was higher in clonidine group compare to butorphanol group from around 15 min up to 6 hrs.

Kumkum Gupta et al,11 observed that all patients in their study showed a significant decrease in heart rate and MBP from baseline values, but magnitude of decrease was lesser with patients of butorphanol group as compared to patients of clonidine group.

\section{Hypotension}

A low incidence of side effects was observed in our study. 3 patients (10 \%) had hypotension in Group BC and In Group BB 1 patient $(3.33 \%)$ had hypotension. These patients were treated with $6 \mathrm{mg}$ of Mephentermine I.V. Sunil B.V. et al,15 observed hypotension in 4 patients $(13.33 \%)$ in clonidine group. Binaykumar et al, ${ }^{16}$ observed hypotension in 2 patients $(5 \%)$ in the butorphanol group.

\section{Bradycardia}

3 patients (10 \%) had bradycardia in Group BC and In Group BB 1 patient $(3.33 \%)$ had bradycardia these patients were treated with $0.6 \mathrm{mg}$ atropine I.V. Sunil B.V. et al. ${ }^{15}$ observed bradycardia in 3 patients (10\%) in clonidine group.

\section{Sedation}

There was no significant difference noted in respiratory rate and spo 2 in any patients during the study period. Although the patients in clonidine group were well sedated (Campbell sedation score at $1.6+0.62$ at $30 \mathrm{~min}$ and $1.4+0.50$ at 150 min) compare to butorphanol group (Campbell sedation score at $0.5+0.50$ at $30 \mathrm{~min}$ and $0.46+0.50$ at $150 \mathrm{~min}$ ).

Kumkum Gupta et al.,11 observed that patients in clonidine group were sedated as compared to butorphanol group but none of the patients had respiratory depression or desaturation during the study period.

\section{CONCLUSIONS}

When clonidine and butorphanol are used as an adjuvant to hyperbaric bupivacaine for spinal anaesthesia, clonidine provides longer duration of sensory and motor block compared to butorphanol. Duration of analgesia was also longer with clonidine, which delayed the time for first analgesic request compared to butorphanol. No significant haemodynamic changes or adverse effects were noted with either adjuvants.

In a nutshell, clonidine is a good adjuvant to hyperbaric bupivacaine for spinal anaesthesia with good haemodynamic stability and longer analgesia without any adverse effects.

Data sharing statement provided by the authors is available with the full text of this article at jemds.com.

Financial or other competing interests: None.

Disclosure forms provided by the authors are available with the full text of this article at jemds.com.

\section{REFERENCES}

[1] Bier A. Versuche uber cocainisirung des ruckenmarkes. Dtsch Z Chir 1899;51:361-9.

[2] Churchill DHC. Spinal and epidural block. In: Wylie, Churchill DHC, eds. A practice of anaesthesia. $7^{\text {th }}$ edn. London: 2003. p. 608.

[3] Lambert DH. Factors influencing spinal anaesthesia. Int Anesthesiol Clin 1989;27(1):13-20.

[4] Yaksh TL, Rudy TA. Analgesia mediated by a direct spinal action of narcotics. Science 1976;192(4246):1357-8.

[5] Wang JK, Nauss LA, Thomas JE. Pain relief by intrathecally applied morhine in man. Anaesthesiology 1979;50(2):149-51.

[6] Eisenach JC, De Kock M, Klimscha W. Alpha 2 adrenergic agonists for regional anaesthesia. A clinical review of clonidine (1984-1995). Anaesthesiology 1996;85(3):65574.

[7] Gordth T, Post C, Olsson Y. Evaluation of toxicity of subarachnoid clonidine, guanfacine and a substance Pantagonist on rat spinal cord and nerve roots: light and electron microscopic observations after chronic intrathecal administration. Anesth Analg 1988;65(12):1303-11.

[8] Kaur M, Katyal S, Kathuria S, et al. A comparative evaluation of intrathecal bupivacaine alone, suffentanil or butorphanol in combination with bupivacaine for endoscopic urological surgery. Saudi J Anaesth 2011;5(2):202-7.

[9] Sangeeta BA, Vanita BA. Efficacy of intrathecal clonidine in perioperative pain relief in hysterectomies. J Pharm Biomed Sci 2014;4(1):09-13.

[10] McCral AF, Wildsmith JA. Prevention and treatment of hypotension during central neuraxial block. Br J Anaesth 1993;70(6):672-80.

[11] Gupta K, Jain M, Gupta PK, et al. clonidine versus butorphanol as adjuvant to $0.5 \%$ hyperbaric bupivacaine to enhance the onset and duration of subarachnoid blockade with postoperative analgesia during orthopedic surgeries - a randomized study. Glob Anaesth Perioper Med 2015.

[12] Reddy GN, Manohar S, Supriya P, et al. Comparison of efficacy of butorphanol and fentanyl as intrathecal adjuvant to bupivacaine. Journal of Medical and Dental Sciences 2015;4(33):5675-81.

[13] Nag S, Kumar R, Najfi S, et al. A comparative study of butorphanol as an adjunct to bupivacaine in comparison 
to bupivacaine alone. Journal of Dental and Medical Sciences 2014;13(1):32-6.

[14] Anandani DN, Shelat SD, Vaniya J, et al. A comparison of intrathecal dexmedetomidine and clonidine as adjuvants to hyperbaric bupivacaine for gynecological surgery. Int J Basic Clin Pharmacol 2015;4:1163-7.

[15] Sunil BV, Jajee PR. Intrathecal clonidine as an adjuvant with hyperbaric bupivacaine for caesarean section.
Journal of Evolution of Medical and Dental Sciences 2014;3(25):6993-7001.

[16] Kumar B, Williams A, Liddle D, et al. Comparison of intrathecal bupivacaine - fentanyl and bupivacainebutorphanol mixtures for lower limb orthopedic procedures. Anesth Essays Res 2011;5(2):190-5. 